\title{
Coseismic Surface GPS Displacement and Ground Shaking Associated with the 2006 Pingtung Earthquake Doublet, Offshore Southern Taiwan
}

\author{
Horng-Yue Chen ${ }^{*}$, Jian-Cheng Lee, Long-Chen Kuo, Shui-Beih Yu, and Chi-Ching Liu \\ Institute of Earth Sciences, Academia Sinica, Taipei, Taiwan, ROC
}

Received 31 December 2007, accepted 26 September 2008

\begin{abstract}
Two successive large earthquakes $\left(\mathrm{M}_{\mathrm{L}}=6.96\right.$ and 6.99) occurred in southern Taiwan offshore of the Hengchun town, Pingtung county, with the two main shocks separated by an interval of only 8 minutes. Based on a dense network of continuously recording GPS stations (CORS) in Taiwan and adopting two different post-processing methods, we estimate the coseismic displacements and characterize their ground motions. Daily solution algorithm is used to determine the total coseismic displacements of the dual main shocks from 30-second sampling rate data; however the coseismic displacement for the individual main shock cannot be resolved. We thus adopt the kinematic positioning technique using 1 -second sampling rate $(1 \mathrm{~Hz})$ data to determine the individual coseismic displacements for each main shock as well as the evolution of the ground shaking. The results show only three stations near the epicenters with significant total coseismic displacements of $3-5$ centimeters. We find that the stations farther north of the epicenters area indeed reveal significant coseismic displacements but moving in the opposite direction between the two main shocks. The coseismic displacement of the first main shock is consistent with a NNE-trending normal faulting in the lower crust offshore of southern Taiwan, while that of the second main shock likely agrees with an ENE-trending right-lateral strike-slip faulting, although the possibility of a NNW-trending left-lateral strike-slip faulting cannot be ruled out. The $1 \mathrm{~Hz}$ GPS data can record the coseismic ground shaking in great detail, including the first motion direction and the amplitude and arrival time, which are comparable to the seismometer data. By applying an exponential attenuation behavior with hypocenter distance we observe that four stations in the coastal plain exhibit relatively larger amplitudes of the ground shaking, implying a significant influence of thick unconsolidated deposits in that area.
\end{abstract}

Key words: GPS, CORS, Coseismic deformation, Seismic ground shaking, Pingtung earthquake

Citation: Chen, H. Y., J. C. Lee, L. C. Kuo, S. B. Yu, and C. C. Liu, 2008: Coseismic surface GPS displacement and ground shaking associated with the 2006 Pingtung earthquake doublet, offshore southern Taiwan. Terr. Atmos. Ocean. Sci., 19, 683-696, doi: 10.3319/TAO.2008.19.6.683(PT)

\section{INTRODUCTION}

Two successive major earthquakes with magnitudes $\mathrm{M}_{\mathrm{L}}=6.96$ and 6.99 occurred only eight minutes apart in time approximate 40 and $33 \mathrm{~km}$, respectively, offshore of the Hengchun Peninsula, Pingtung county, in the southern tip of Taiwan (Fig. 1) on 26 December 2006 (CWB 2006). This earthquake sequence was the largest magnitude of dual main shocks during Taiwan's century-long history of instrumental record of earthquakes (TEC 2007). Although the hypocenters of the main shocks occurred rather deep in the lower crust at 44 and $50 \mathrm{~km}$ depth, they caused some casualty and serious property damages around the town of Hengchun.

A dense GPS network covering the whole Taiwan island

\footnotetext{
* Corresponding author

E-mail: chenhy@earth.sinica.edu.tw
}

with more than 300 CORS (continuously recording GPS stations) in Taiwan has been set up by a joint effort of different agencies since 2001 - Central Weather Bureau (CWB), Ministry of the Interior (MOI), National Land Surveying and Mapping Center (NLSC), Institute of Earth Sciences, Academia Sinica (IESAS), and several other institutes and universities. Most of the CORS stations are equipped with 1 second $(1 \mathrm{~Hz})$ and 30 seconds dual sampling rates, except the stations of NLSC with only $1 \mathrm{~Hz}$. The data are collected in real time and transmitted within 10 days through Internet to the data center in IESAS and computed into daily solutions in IESAS (2007) (http:// gps.earth.sinica.edu.tw).

We used the daily solution estimated from the 30 -second data from the 300 CORS stations to obtain the coseismic 


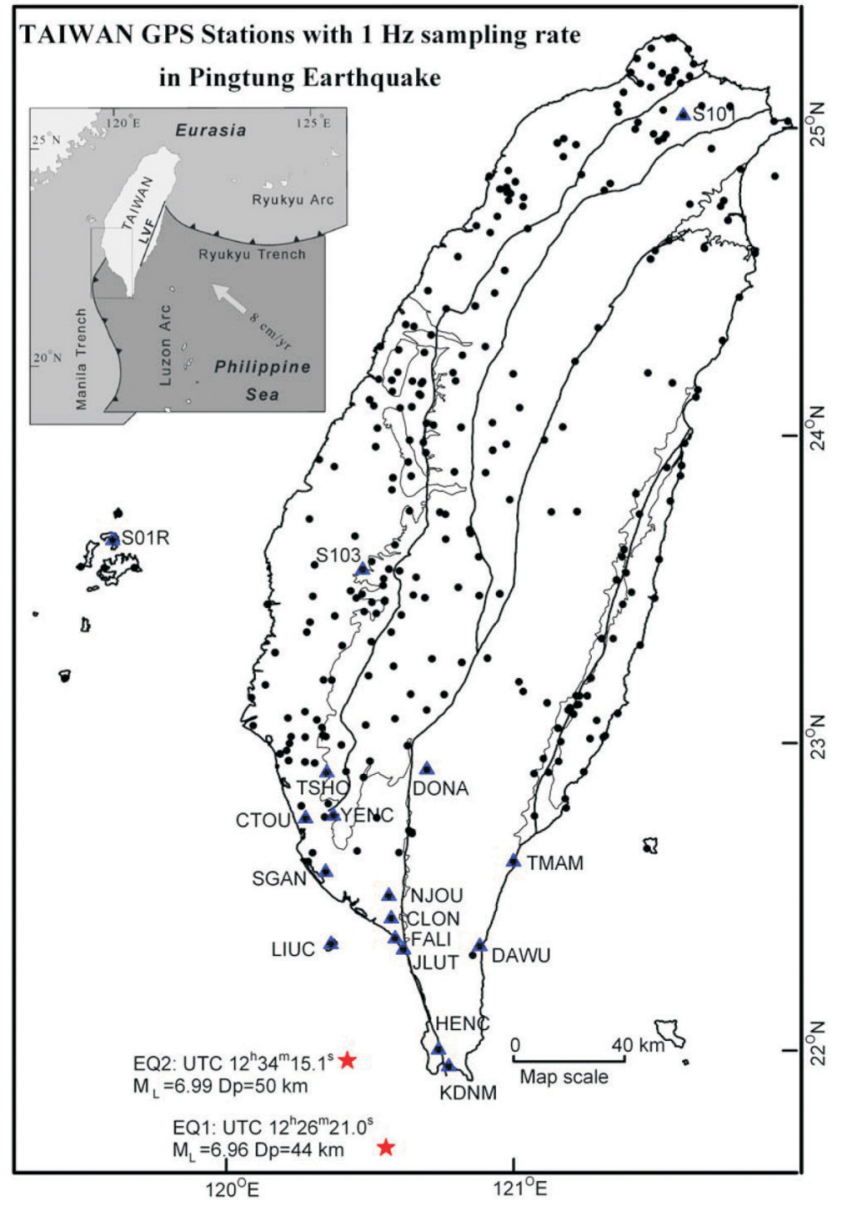

Fig. 1. The CORS (Continuous Observation Recording GPS Stations) of Taiwan. 16 stations with $1 \mathrm{~Hz}$ sampling near the epicenters of the 2006 Pingtung dual-event earthquakes have been selected for detailed analyses, denoted in solid triangle. The two star represent locations of the epicenters of the two main shocks. The inset shows the regional tectonic framework characterized by a rapid convergence rate of $8 \mathrm{~cm} \mathrm{yr}^{-1}$ between Eurasia and the Philippine Sea.

displacement field. However, because of the dual events, the coseismic displacements for the individual main shock are difficult to determine with solely the 30 -second data in the conventional way. In this study, we adopt the $1-\mathrm{Hz}$ kinematic positioning to estimate the coseismic surface displacements for each main shock. Furthermore, we used 1-Hz data at 16 stations around the epicenters area (Fig. 1) to better characterize the instantaneously seismic motions. We then compare the ground shaking records of GPS to seismometers and discuss their differences, and the likely exponential attenuation of the coseismic GPS ground movements with respect to the distance to the hypocenters.

\section{DATA ACQUISITION AND PROCESSING}

The real time or near-real time CORS data are stored by two modules applying the ring buffer, at both $1-\mathrm{Hz}$ and
30 -second sampling rates. In the current storage capacity, it can store $1-\mathrm{Hz}$ rate for 48 hours and 30 -second samplings for over 1 month. Once an earthquake occurs, $1-\mathrm{Hz}$ data of the stations closest to the main shock will be downloaded manually through remote control within a short time. Most of the 30-second data, except the instantaneous stations of IESAS, were obtained in two weeks, and the daily solutions can be obtained in a short time (Kuo 2001; Chen et al. 2003). The data processing of the CORS for kinematic positioning of daily solutions is in the post processing mode, under the standard algorithm of Bernese V5.0 (Dach et al. 2007). An outlier detection algorithm and filtering remove the seasonal and sidereal repeat noises (Bock et al. 2000; Dong et al. 2006), we also employed a sliding 2-sidereal-day window to eliminate the sidereal period noise, such as multipath and phase center variation (Bock et al. 2000).

The station S101, located at the northern end of Taiwan, was adopted as the reference station to define the minimum constrained conditions to its value in the International Terrestrial Reference Frame 2000 (ITRF00).

For the 2006 Pingtung earthquake, considering station conditions and data transmission facilities, 16 stations near the epicenter in southern Taiwan plus the referenced station $\mathrm{S} 101$ at $1 \mathrm{~Hz}$ are selected for processing the kinematic positioning. As 1-Hz GPS recording of Fig. 2 reveals, the common noises during the coseismic ground shaking can be removed by comparing the data during the earthquake (Day 360) and those of the following day (Day 361). As a result, we obtain a more stable trend of station positioning for all three components, especially in the vertical component.

As for the trend of station positioning, we combine the daily solutions to obtain weekly solutions one week before and one week after the earthquakes, after estimating the daily solutions from the 30 -second data. Note that we exclude the solution at the day of the earthquakes. The differences between the weekly solutions before and after the earthquake doublet thus represent the total coseismic displacements. For instance, station HENC, which is closest to the epicenter, indicates a significant coseismic movement, especially in the east and up components (Fig. 3). For the total coseismic displacements, we calculate data of all CORS 300 stations in the Taiwan area.

\section{COSEISMIC DEFORMATION AND GROUND SHAKING}

By comparing the weekly solutions from 30 -second data before and after the main shocks, we obtain the total coseismic displacement shown in Table 1 and Fig. 4. Only a few stations near the epicenters such as HENC, LIUC, KDNM, and JLUT in southern Taiwan showed significant coseismic displacements up to $4 \mathrm{~cm}$, while other stations farther away revealed relatively large uncertainties.

For determining coseismic displacements for each of the 
two main shocks only eight minutes apart, we adopt the $1-\mathrm{Hz}$ GPS data for kinematic positioning, because the 30-second data appeared to be too coarse to allow the appropriatedetermination. In contrast, with the detailed records of $1-\mathrm{Hz}$ data, we are able to determine the coseismic displacements under a significant noise of ground shaking during tens to hundreds of seconds following the arrival of the first seismic waves (Fig. 5). The coseismic displacements of the main shock from the aforementioned 17 stations as shown in Table 2 and Fig. 6.

For the first main shock, the horizontal coseismic displacements show two groups of stations moving in opposite directions (Fig. 6a). The two southern stations HENC and KDNM, which are closest to the epicenter, moved toward southwest. The other 14 northern stations farther away from the epicenter mostly moved toward southeast to east. For the vertical component, although with relatively large uncertainties, we can observe a general small coseismic uplift of a few centimeters in the northern group and a subsidence of a few centimeters in the southern group (Table 2). Geologically speaking, the pattern of these coseismic displacements is consistent with NNE-SSW trending normal faulting derived from seismological information (BATS this issue) near the southern tip of Taiwan, that pulled the latter downward toward the SW. This deep normal faulting of $40-50 \mathrm{~km}$ in depth likely occurs in the eastward subduction slab and can be interpreted as a result of relaxation or detachment of the slab with an ENE-WSW extension. On the other hand, for the SE to E horizontal movement coupled with a slight uplift north of the coseismic fault patch (i.e., the northern group), we interpret it as an elastic rebound in an area not only outside the normal fault of the first main shock but also under interseismic E-W contraction stress regime of plate collision prior to the Pingtung earthquake.

For the second main shock (Fig. 6b), only the stations near the epicenter (e.g., HENC, LIUC, KDNM, and JLUT), (a) Ground motion at station HENC with respect to station S101
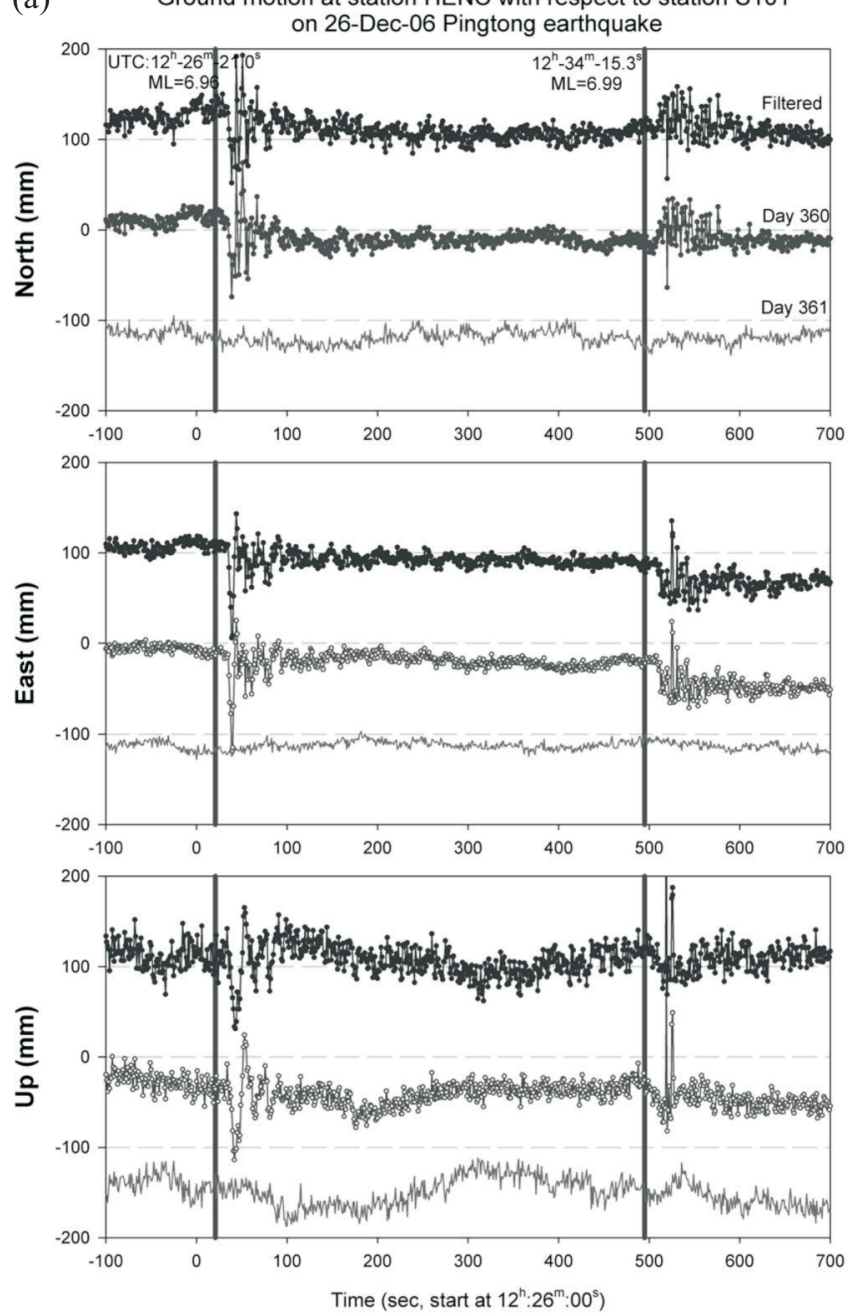

(b) Ground motion at station LIUC with respect to station S101
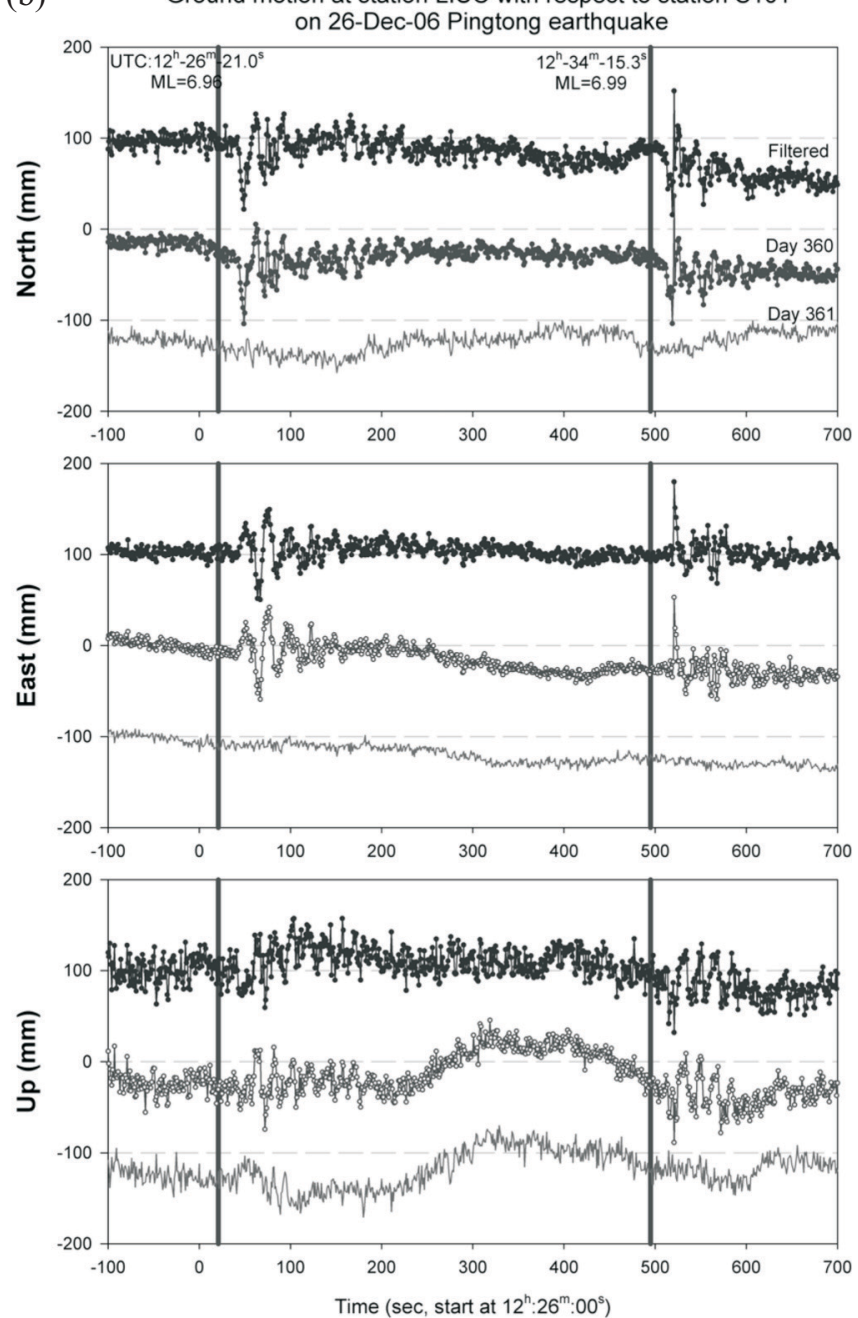

Fig. 2. Records of $1 \mathrm{~Hz}$ GPS data at two near stations, HENC and LIUC, during the 2006 Pingtung earthquakes. A filter algorithm was applied to remove the sidereal repeat noises. The records of the following day (Day 361) of the earthquake were used for comparison to obtain the filtered data. 


\section{(a) HENC}
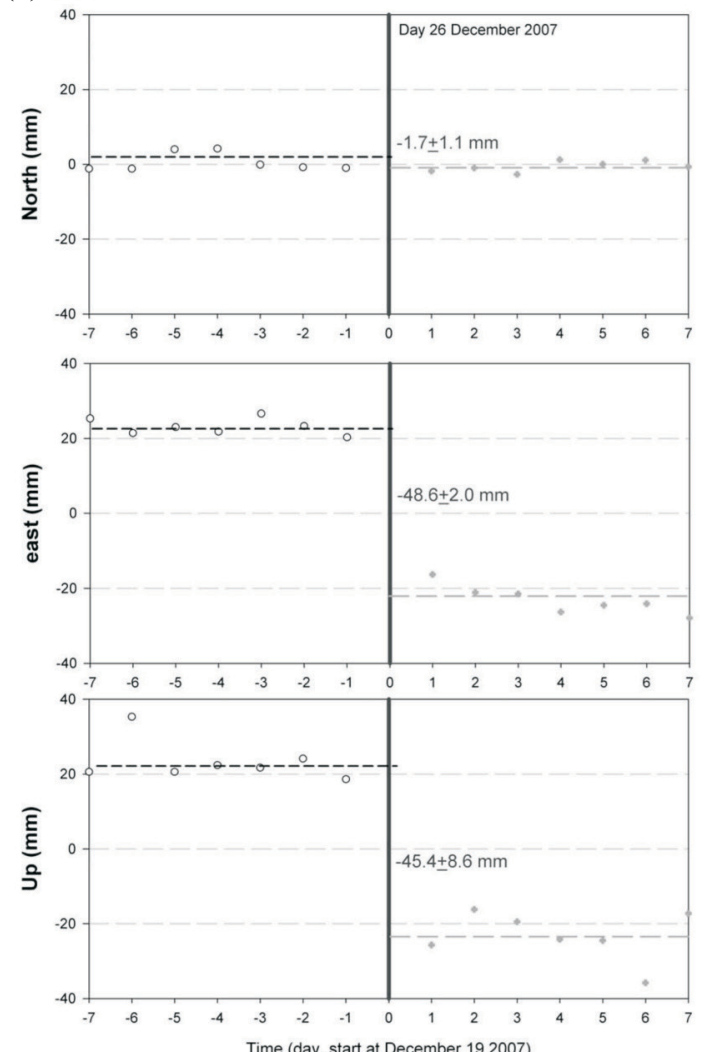

(c) JLUT
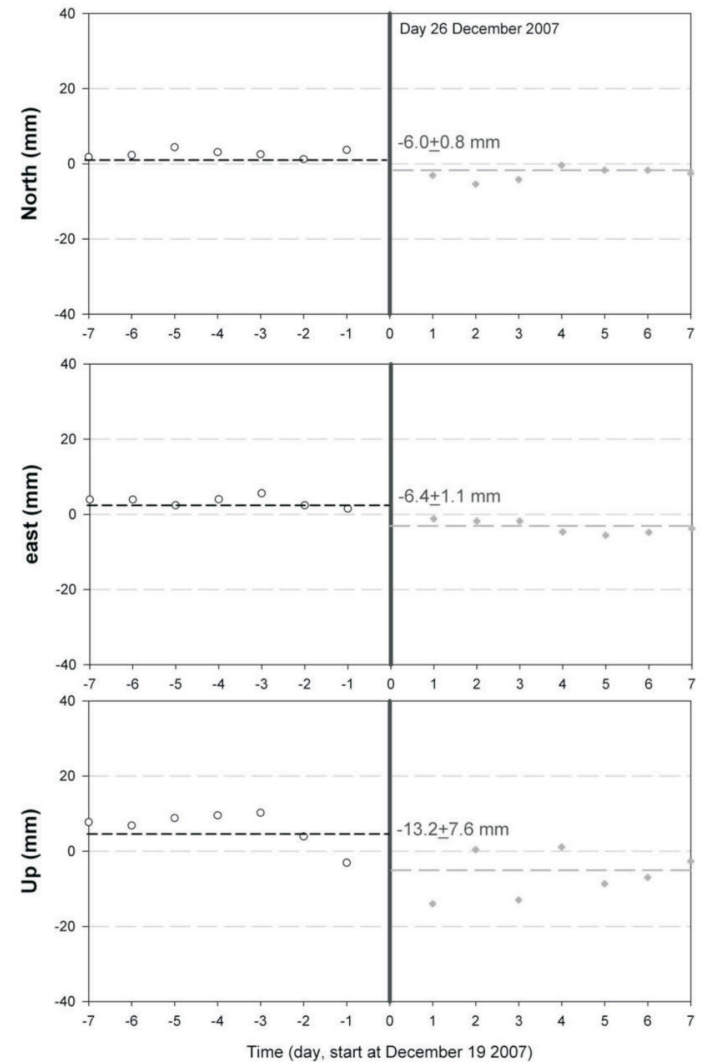

(b) KDNM
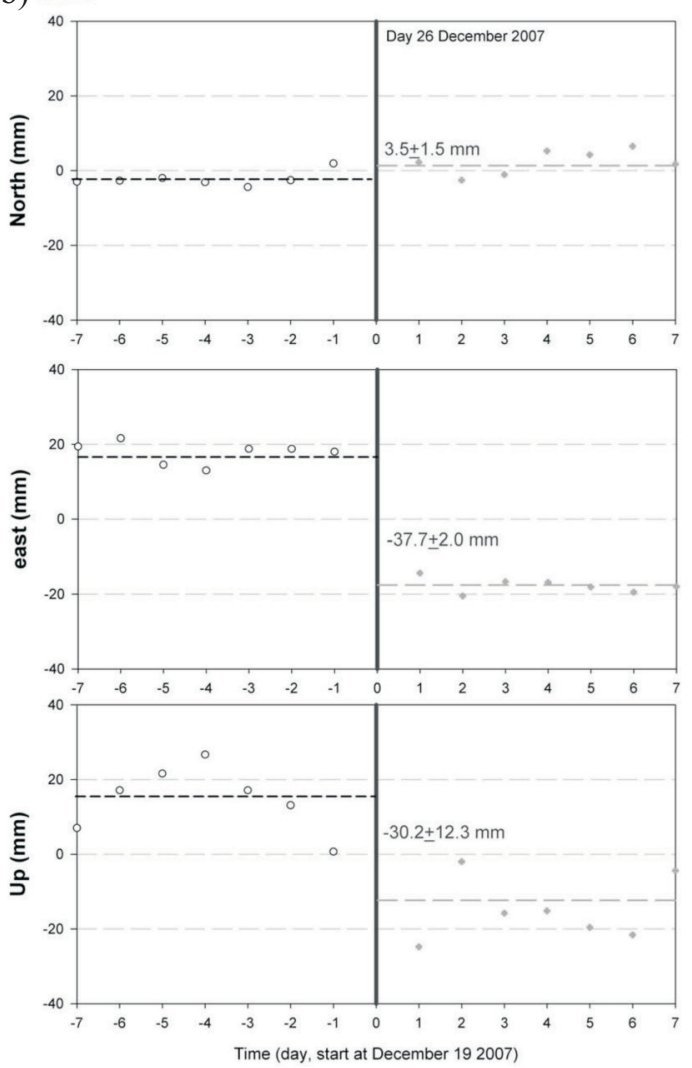

(d) LIUC
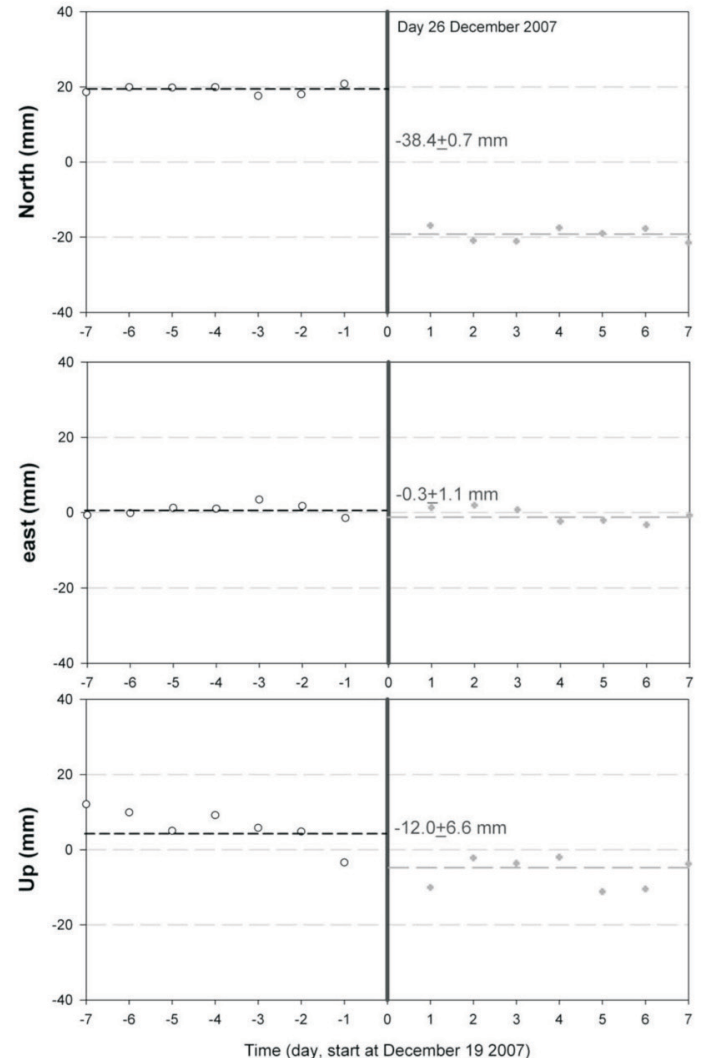

Fig. 3. Determination of the total coseismic displacements from daily and weekly solutions before and after the Pingtung earthquakes. The weekly solutions were the average of daily solution calculated by standard processes. 
Table 1. Total coseismic displacements combined two main shocks of the Pingtung earthquake computed by daily solution estimated from 30second data at 16 continuous GPS stations in the southern Taiwan.

\begin{tabular}{lrrr}
\hline Stations & $\mathbf{d N}(\mathbf{m m})$ & $\mathbf{d E}(\mathbf{m m})$ & $\mathbf{d h}(\mathbf{m m})$ \\
\hline CLON & $-2.0 \pm 1.1$ & $-2.0 \pm 1.6$ & $-9.7 \pm 24.6$ \\
CTOU & $-0.5 \pm 0.6$ & $-0.2 \pm 1.1$ & $-4.1 \pm 24.7$ \\
DAWU & $1.5 \pm 0.7$ & $-4.3 \pm 1.3$ & $-10.7 \pm 25.1$ \\
DONA & $3.0 \pm 0.8$ & $0.9 \pm 0.9$ & $-2.6 \pm 25.4$ \\
FALI & $-4.6 \pm 0.6$ & $-4.3 \pm 1.2$ & $-12.9 \pm 27.1$ \\
HENC & $-1.7 \pm 1.1$ & $-48.6 \pm 2.0$ & $-45.4 \pm 30.4$ \\
JLUT & $-6.0 \pm 0.8$ & $-6.4 \pm 1.1$ & $-13.2 \pm 31.4$ \\
KDNM & $3.5 \pm 1.5$ & $-37.7 \pm 1.6$ & $-30.2 \pm 32.2$ \\
LIUC & $-38.4 \pm 0.7$ & $-0.3 \pm 1.1$ & $-12.0 \pm 33.4$ \\
NJOU & $0.4 \pm 1.0$ & $-0.4 \pm 1.1$ & $-7.1 \pm 35.3$ \\
S01R & $-0.3 \pm 0.0$ & $0.6 \pm 0.1$ & $0.0 \pm 37.1$ \\
S103 & $0.0 \pm 0.5$ & $1.5 \pm 1.1$ & $-0.1 \pm 37.2$ \\
SGAN & $-1.5 \pm 3.7$ & $-4.2 \pm 4.9$ & $-6.2 \pm 38.4$ \\
TMAM & $2.3 \pm 0.8$ & $1.1 \pm 1.2$ & $-3.1 \pm 42.1$ \\
TSHO & $0.9 \pm 0.4$ & $1.2 \pm 1.0$ & $1.7 \pm 50.2$ \\
YENC & $-0.5 \pm 0.6$ & $-1.0 \pm 1.1$ & $-2.2 \pm 44.1$ \\
\hline
\end{tabular}

Coseismic Displacement in 2006 Pingtung Earthquake Doublet

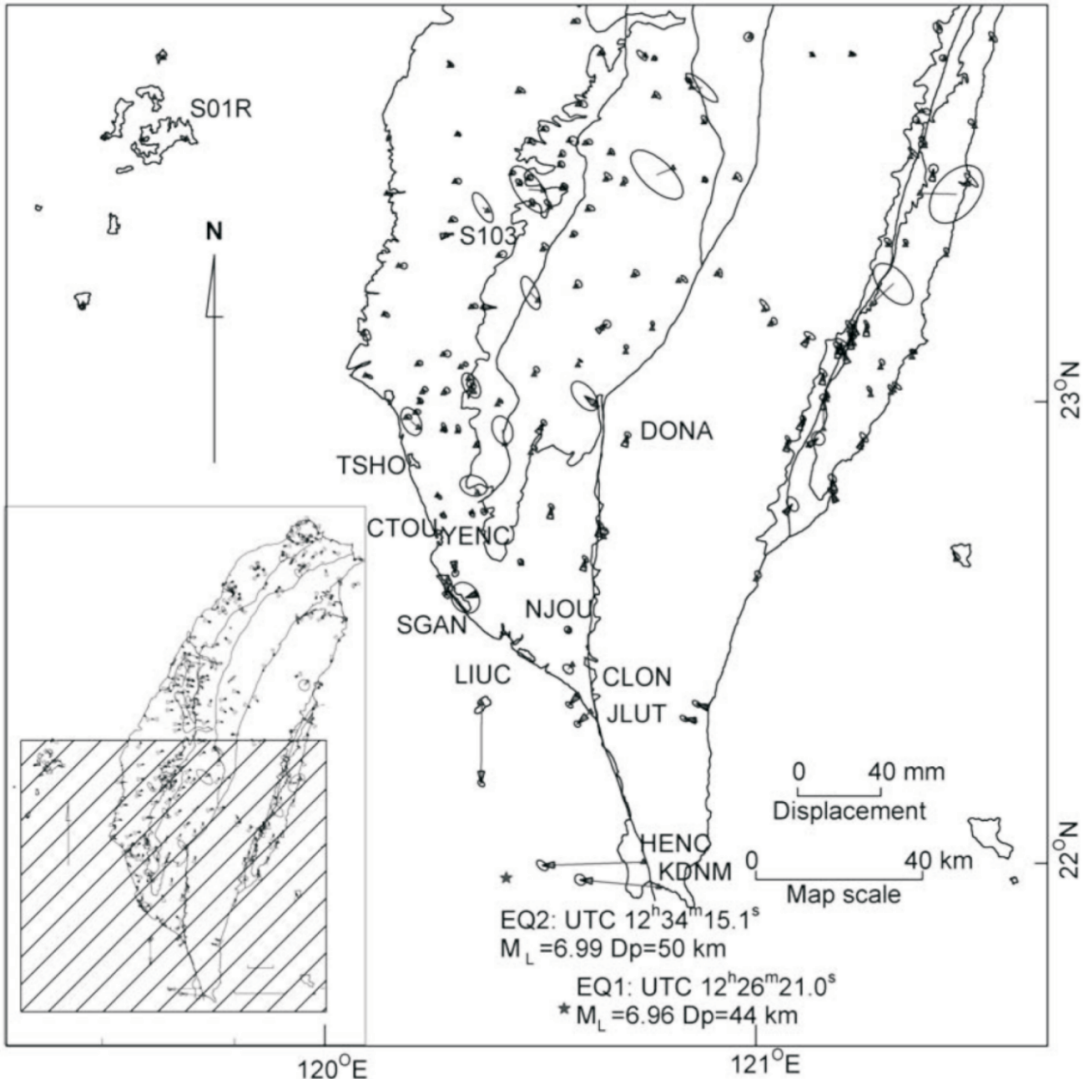

Fig. 4. The total coseismic displacements of dual shocks of the 2006 Pingtung earthquake determined from two weeks of daily solutions. Only three stations near the epicenters produced significant coseismic displacements: KDNM, HENC, and LIUC. 
(a) HENC
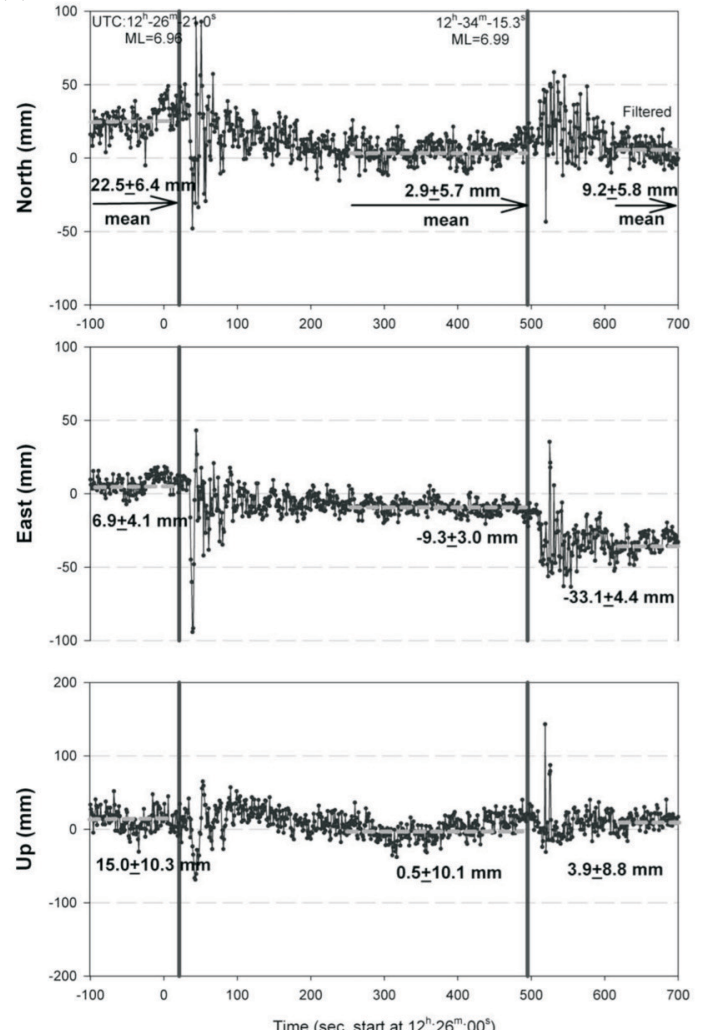

(c) KDNM
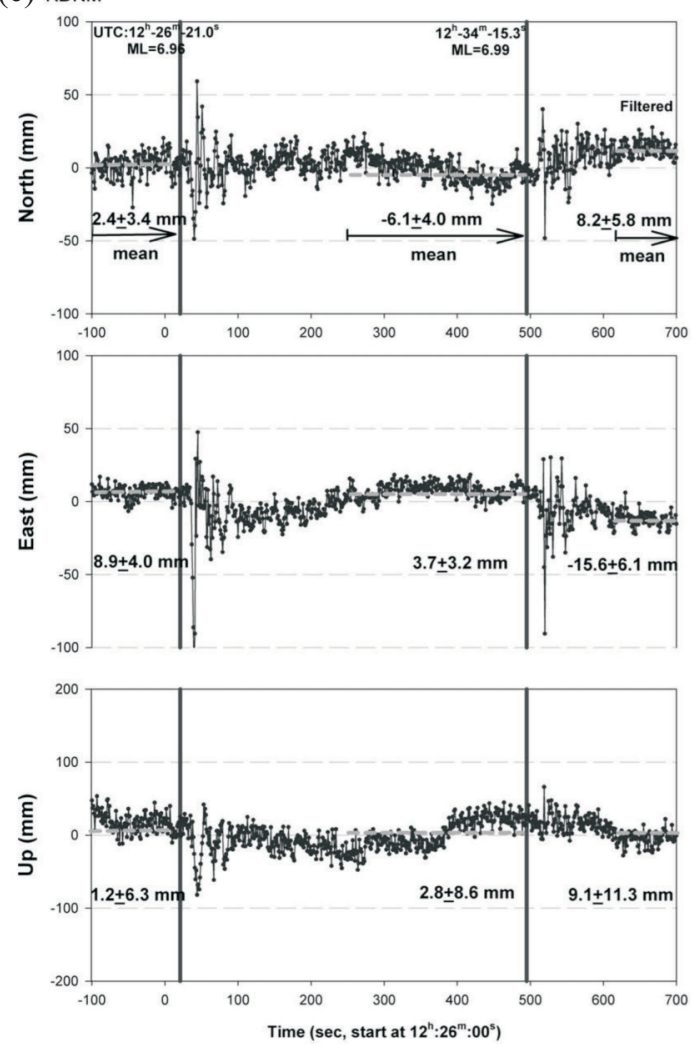

(b) JLUT
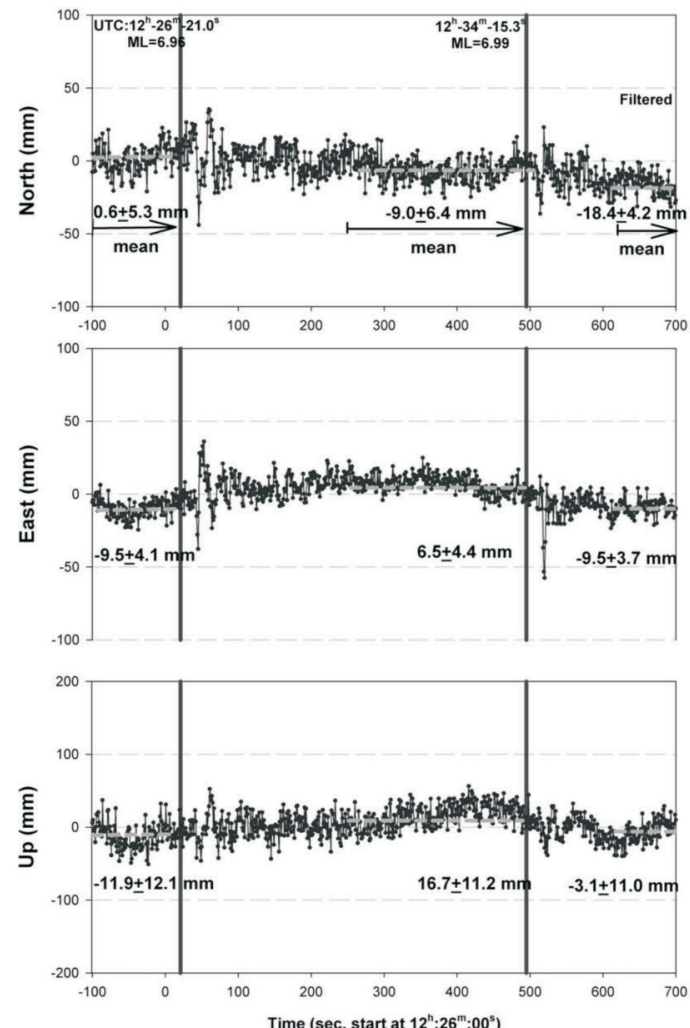

(d) LIUC
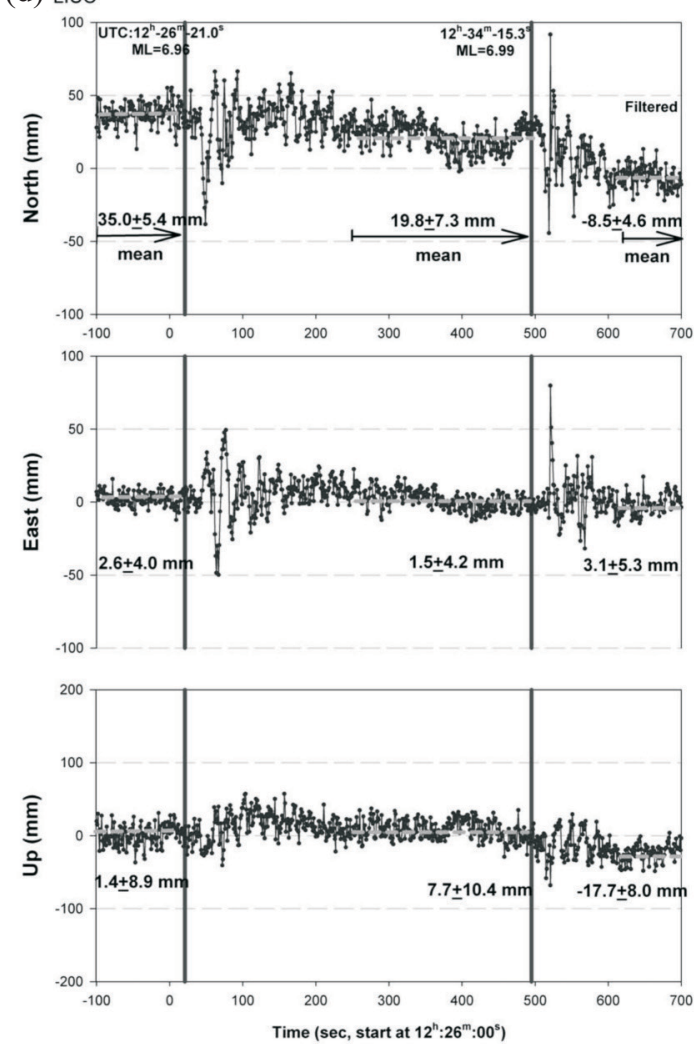

Fig. 5. Examples of determination of individual coseismic displacements for each main shock from 1 Hz GPS data by kinematic positioning algorithm. (a) Station HENC. (b) Station JLUT. (c) Station KDNM. (d) Station LIUC. The positioning seems to stabilize after 100 - 200 seconds following the main shocks. Note that the vertical (Up) component is of larger uncertainty than the horizontal components. 
Table 2. Individual coseismic displacements of two main shocks of the Pingtung earthquake computed by $1 \mathrm{~Hz}$ data from 16 GPS stations in southern Taiwan.

\begin{tabular}{|c|c|c|c|c|c|c|}
\hline \multirow{2}{*}{ Stations } & \multicolumn{3}{|c|}{ EQ1 (UTC: $12^{\mathrm{h}} 26^{\mathrm{m}} 21.0^{\mathrm{s}}$ ) } & \multicolumn{3}{|c|}{ EQ2 (UTC: $12^{\mathrm{h}} 34^{\mathrm{m}} 15.3^{\mathrm{s}}$ ) } \\
\hline & $\mathbf{d N}(\mathbf{m m})$ & $\mathrm{dE}(\mathrm{mm})$ & dh (mm) & $\mathrm{dN}(\mathbf{m m})$ & dE (mm) & dh (mm) \\
\hline CLON & $-2.6 \pm 9.1$ & $14.7 \pm 5.7$ & $17.3 \pm 14.8$ & $-2.0 \pm 6.6$ & $-6.5 \pm 5.0$ & $-9.7 \pm 14.1$ \\
\hline CTOU & $-12.5 \pm 8.3$ & $6.9 \pm 6.2$ & $-0.6 \pm 15.1$ & $0.3 \pm 7.6$ & $0.3 \pm 6.2$ & $-14.0 \pm 13.2$ \\
\hline DAWU & $-1.1 \pm 8.4$ & $16.7 \pm 6.1$ & $-2.4 \pm 15.3$ & $0.1 \pm 6.9$ & $-16.4 \pm 4.9$ & $1.2 \pm 13.1$ \\
\hline DONA & $-3.0 \pm 8.1$ & $12.7 \pm 5.2$ & $6.4 \pm 13.3$ & $4.7 \pm 6.9$ & $-4.7 \pm 5.1$ & $-16.1 \pm 12.4$ \\
\hline FALI & $-14.5 \pm 8.5$ & $17.7 \pm 5.5$ & $7.6 \pm 15.9$ & $0.0 \pm 7.4$ & $-11.7 \pm 5.0$ & $0.0 \pm 13.7$ \\
\hline HENC & $-19.6 \pm 8.6$ & $-16.2 \pm 5.0$ & $-14.5 \pm 14.4$ & $6.3 \pm 8.1$ & $-23.8 \pm 5.3$ & $4.3 \pm 13.3$ \\
\hline JLUT & $-8.4 \pm 8.3$ & $16.0 \pm 6.0$ & $28.6 \pm 16.5$ & $-9.4 \pm 7.4$ & $-16.0 \pm 5.7$ & $-19.8 \pm 15.7$ \\
\hline KDNM & $-8.5 \pm 5.1$ & $-5.2 \pm 5.1$ & $1.6 \pm 10.6$ & $14.3 \pm 7.5$ & $-19.3 \pm 6.8$ & $6.3 \pm 14.2$ \\
\hline LIUC & $-15.2 \pm 9.1$ & $-1.2 \pm 5.7$ & $6.3 \pm 13.7$ & $-28.3 \pm 8.6$ & $1.5 \pm 6.8$ & $-25.4 \pm 13.1$ \\
\hline NJOU & $-12.5 \pm 9.2$ & $17.9 \pm 4.9$ & $-7.6 \pm 12.0$ & $-0.8 \pm 7.1$ & $-4.0 \pm 5.8$ & $5.2 \pm 13.3$ \\
\hline S01R & $-9.0 \pm 10.4$ & $5.3 \pm 3.9$ & $10.8 \pm 13.7$ & $-3.2 \pm 6.1$ & $0.2 \pm 4.0$ & $-13.5 \pm 12.7$ \\
\hline S103 & $1.1 \pm 7.6$ & $4.9 \pm 4.1$ & $1.1 \pm 11.9$ & $4.7 \pm 6.7$ & $0.3 \pm 4.3$ & $4.7 \pm 12.4$ \\
\hline SGAN & $-5.6 \pm 7.6$ & $15.0 \pm 5.2$ & $32.3 \pm 15.3$ & $6.1 \pm 7.1$ & $-0.2 \pm 5.9$ & $-13.7 \pm 14.7$ \\
\hline TMAM & $-1.8 \pm 7.5$ & $17.5 \pm 4.3$ & $2.0 \pm 12.6$ & $6.5 \pm 6.4$ & $-3.5 \pm 4.5$ & $13.2 \pm 12.3$ \\
\hline TSHO & $-8.8 \pm 9.1$ & $5.2 \pm 5.7$ & $-4.0 \pm 16.7$ & $-0.8 \pm 8.8$ & $0.4 \pm 5.9$ & $-10.4 \pm 16.1$ \\
\hline YENC & $-14.5 \pm 8.6$ & $6.8 \pm 6.0$ & $-5.3 \pm 15.1$ & $5.1 \pm 7.4$ & $1.7 \pm 5.4$ & $2.1 \pm 13.5$ \\
\hline
\end{tabular}

(a) Coseismic displacements for 1 st main shock computed by $1 \mathrm{~Hz}$ data

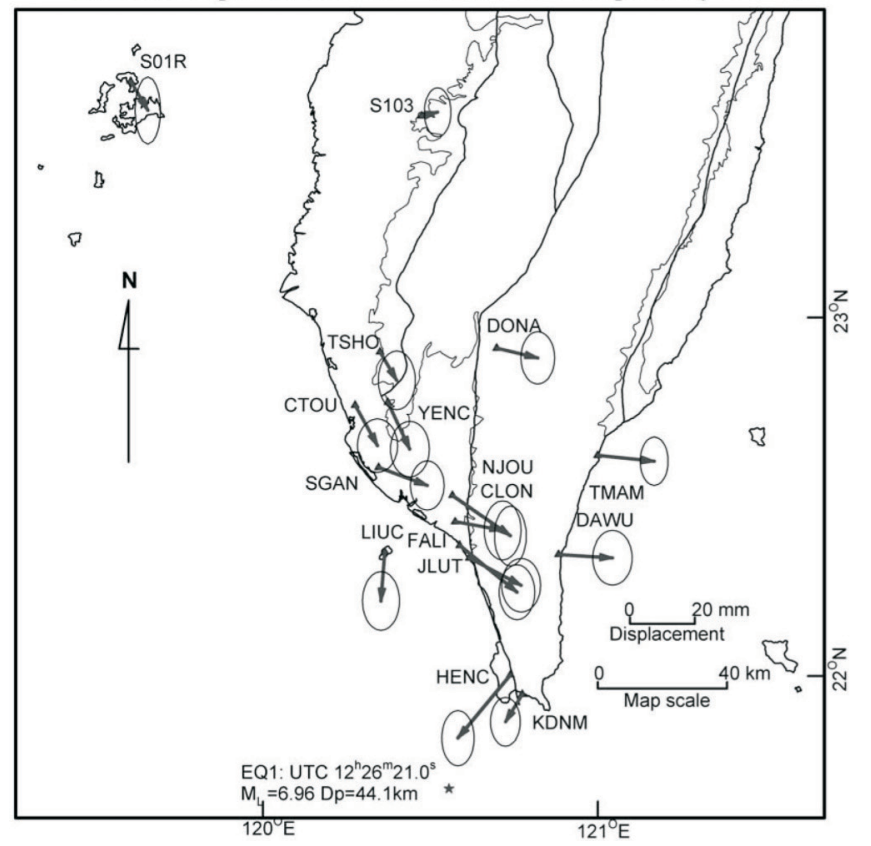

(b) Coseismic displacements for $2^{\text {nd }}$ main shock computed by $1 \mathrm{~Hz}$ data

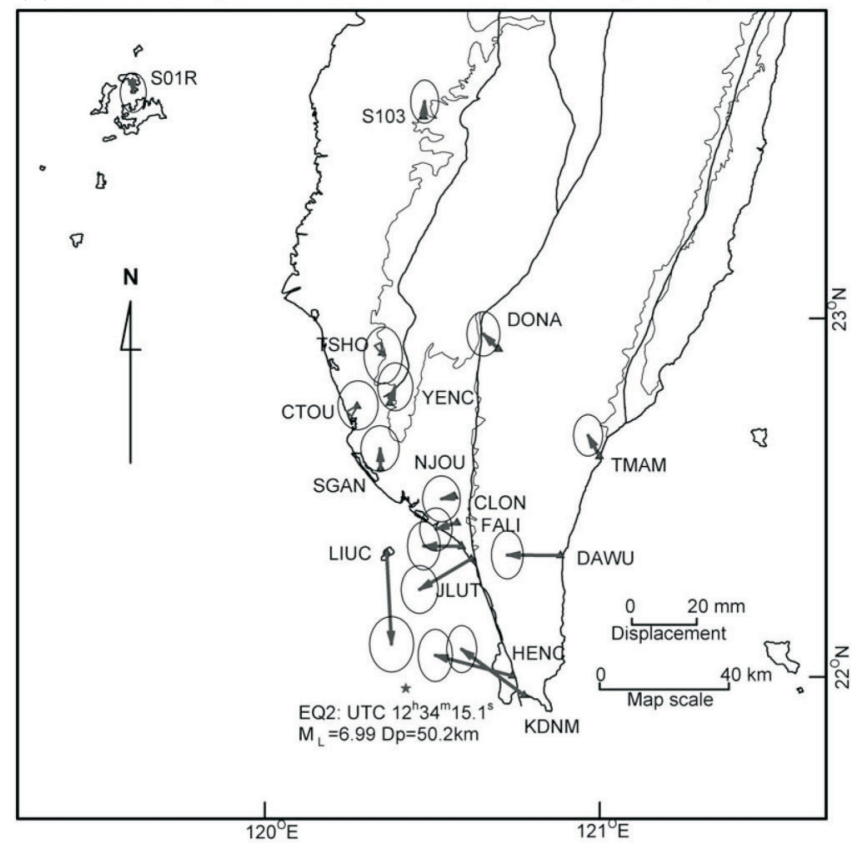

Fig. 6. The individual coseismic displacements from $1 \mathrm{~Hz}$ GPS data through the kinematic positioning algorithm for (a) the first main shock and (b) the second main shock. 
show significant coseismic displacements. In contrast to the first main shock, the coseismic horizontal vectors of the second main shock moved exclusively toward the west except for the LIUC station, which we suspect a non-tectonic effect was involved during the seismic shaking. The focal mechanism of the second main shock indicates strike-slip faulting with a possible ENE-trending right lateral faulting or a NNW-trending left-lateral faulting (BATS this issue), which occurred tens of km north of the first shock. Based on our GPS result of coseismic displacements, the ENE-trending right lateral fault apperas to be the causative fault which separates the two southernmost stations (HENC and KDNM) to the south. For the vertical component, a slight uplift occurred in the southernmost two stations and a slight subsidence occurred in the stations to the north (Table 2), also favoring the ENE-trending fault. It is worth noting that most of the stations generally moved in opposite direction relative to the first main shock, except LIUC and the two stations at the southern tip of Taiwan. From the point of view of tectonic stress, in contrast to the pure E-W extension of the first main shock, the second main shock reveals a stress relaxation of WNW-ESE compression and NNE-SSW extension, which is consistent with the moving direction of the upper crust under the convergence of the Philippine Sea plate and Eurasia.

Thus, based on the GPS coseismic displacements for each main shock we draw the conclusion that the two main shocks of the 2006 Hengchun earthquake doublet are tectonically related despite the fact that they show distinct focal mechanisms. We interpret that the first main shock resulted from a NNE-trending normal faulting at the lower crust and this E-W extension probably is due to the break-up of the subduction along the Manila trench. We interpret the second main shock as occurring on an ENE-trending right-lateral faulting with an E-W compression to compensate the extension strain of the first main shock under the regional compression stress regime of the plate convergence.

Naturally a higher sampling rate of GPS data of $1 \mathrm{~Hz}$ or above can yield more stable and reliable results of kinematic positioning than the 30 -second sampling rate data (Hatanaka et al. 1994; Bock et al. 2000; Ge et al. 2000). Here we study the evolution of surface movement during a short time span of only one minute during the earthquake shaking. We apply the standard post processing algorithm to estimate the positioning second by second, by introducing the estimated atmospheric delay and ambiguities to ionosphere-free linear combination. Figure 7 shows a $40-$ second segment of $1-\mathrm{Hz}$ GPS record of the coseismic ground shaking for all three components at station KDNM. The 1-Hz GPS data are very similar to those from nearby seismometer, which we will discuss in a later section.

Figure 8 shows two examples of evolution of horizontal coseismic ground motion at GPS stations HENC and LIUC. During the first main shock, most of the azimuth of 'the first motion' of the horizontal ground shaking moved toward SE to $\mathrm{SSE}$ with azimuth ranged from $128^{\circ}$ to $168^{\circ}$, except two closer stations HENC and JLUT, which moved significantly toward SW. In more detail, the station HENC (the upper left subplot of Fig. 8) began to move in the SW direction after 16 seconds following the first main shock, rather consistent with the arrival time of the P-wave from the nearby seismometer (Fig. 7). The station LIUC began to move in the SW direction after 24 seconds following the first main shock. In general, the first motion directions are close to the directions of the finite coseismic displacement, together with the coincidence of timing of the first motion and the P-wave, implying that the first motion of ground shaking was mostly triggered by the $\mathrm{P}$-wave of the main shock. To the second main shock, we also observed the similar behavior and the good agreement of (i) motion direction between the first motion of ground shaking and the finite coseismic displacement, and (ii) the timing between the first motion and the arrival time of the $\mathrm{P}$-wave.

We then estimate the maximum displacements of ground shaking for each GPS station. In addition, we also estimate 'the time to affect' for all stations, that is, the duration from the main shock to attending the maximum displacement (Table 3). During the first main shock, the largest amplitude of the instantaneous displacements of coseismic ground shaking occurred near the epicenter and reached 142 and $136 \mathrm{~mm}$ in horizontal component at stations HENC and KDNM, respectively, and 84 and $101 \mathrm{~mm}$ in vertical component. During the second main shock, the largest amplitude of the coseismic ground shaking occurred at stations LIUC and KDNM with 104 and $108 \mathrm{~mm}$ for horizontal component and 88 and $58 \mathrm{~mm}$ for vertical component. Not surprisingly, the largest amplitude of the coseismic ground shaking of the second main shock also occurred at the station near the epicenter area.

\section{DISCUSSION}

\subsection{Comparison of $1-\mathrm{Hz}$ and 30 -second GPS Determination of Total Coseismic Displacement}

We compared the total coseismic displacements obtained from two different techniques (kinematic positioning of $1-\mathrm{Hz}$ GPS data in Table 1 and daily solution from 30-second GPS data in Table 2). The difference of the horizontal coseismic displacements of the main shock are 11.6 and $8.6 \mathrm{~mm}$ at station HENC, and 5.1 and $0.6 \mathrm{~mm}$ at the station LIUC in the north and east components, respectively. Due to the large uncertainties of the filtered kinematic solutions $(5 \sim 8 \mathrm{~mm}$ in the horizontal component, and $14 \mathrm{~mm}$ to the up component of the Table 1), and without considering the effect of the postseismic displacements, the difference of the total coseismic displacements within $10 \mathrm{~mm}$ is acceptable. As the uncertainty in the vertical component is generally 3 to 5 times larger than the horizontal component (Yu and Chen 1994), it is reasonable that both of Tables 1 and 2 show relatively large but still acceptable uncertainties in the up component. 


\subsection{Comparison of GPS with Seismometer for Ground Shaking Motion}

We compared the 1-Hz CORS GPS data with the seis- mological data of BATS (Broadband Array of Taiwan Seismometer), whose recording rate reaches $100 \mathrm{~Hz}$ ( 0.01 second). The coseismic ground motion from the direct kineamtic positioning of GPS measurements in KDNM station (Fig. 7)
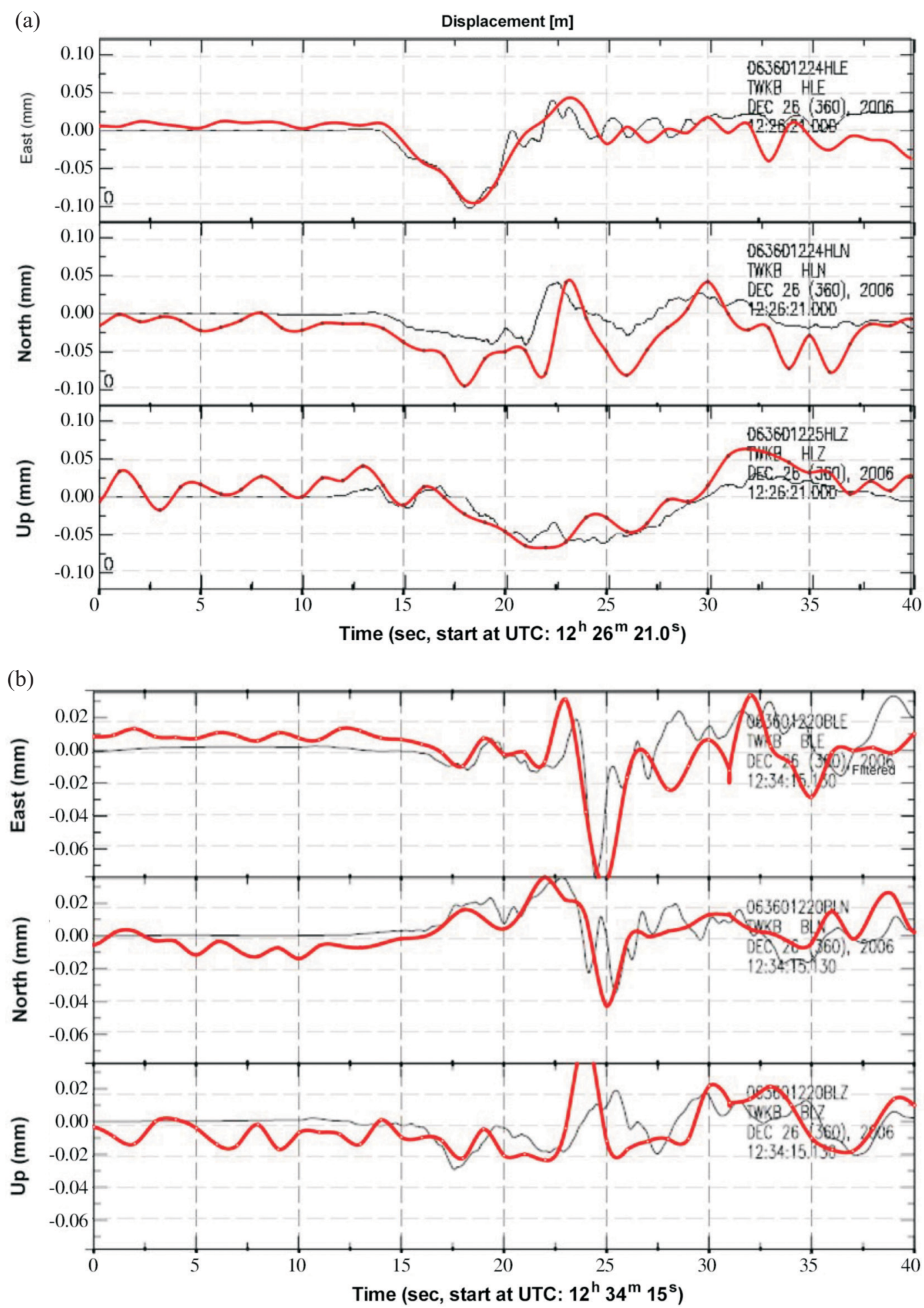

Fig. 7. Detailed records of the seismic ground shaking motion from the directly kineamtic positioning of $1 \mathrm{~Hz}$ GPS measurements (red lines) for all three components fot (a) the first main shock and (b) the second main shock. The black lines represent data from a nearby seismometer, showing a rather consistent motion between the data from $1 \mathrm{~Hz}$ GPS and seismometer. 
(a) First main shock at station HENC with respect to S101, starting at UTC: $12^{\mathrm{h}} 26^{\mathrm{m}} 21^{\mathrm{s}}$

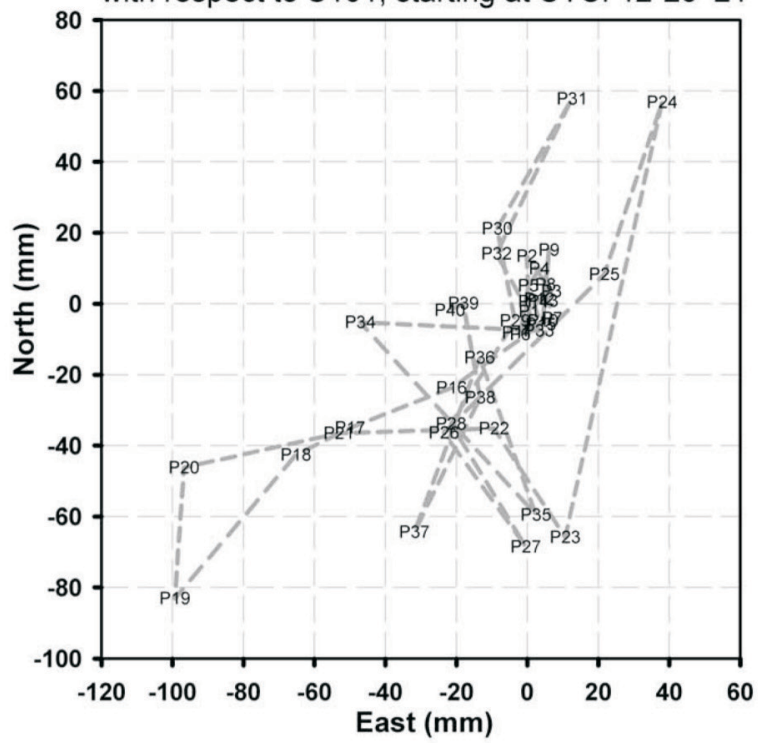

(c) First main shock at station LIUC with respect to S101, starting at UTC: $12^{\mathrm{h}} 26^{\mathrm{m}} 21^{\mathrm{s}}$

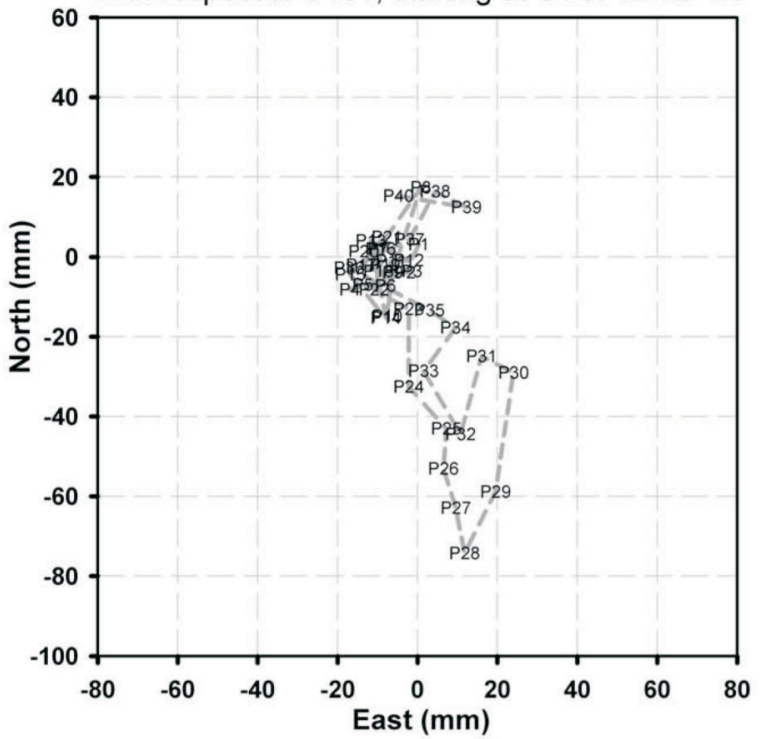

(b) Second main shock at station HENC

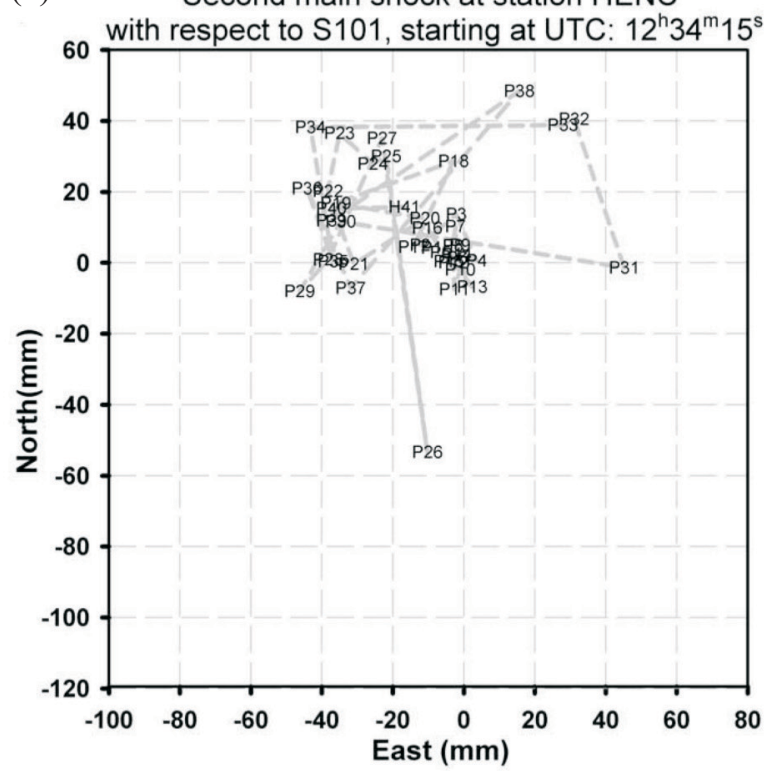

(d)

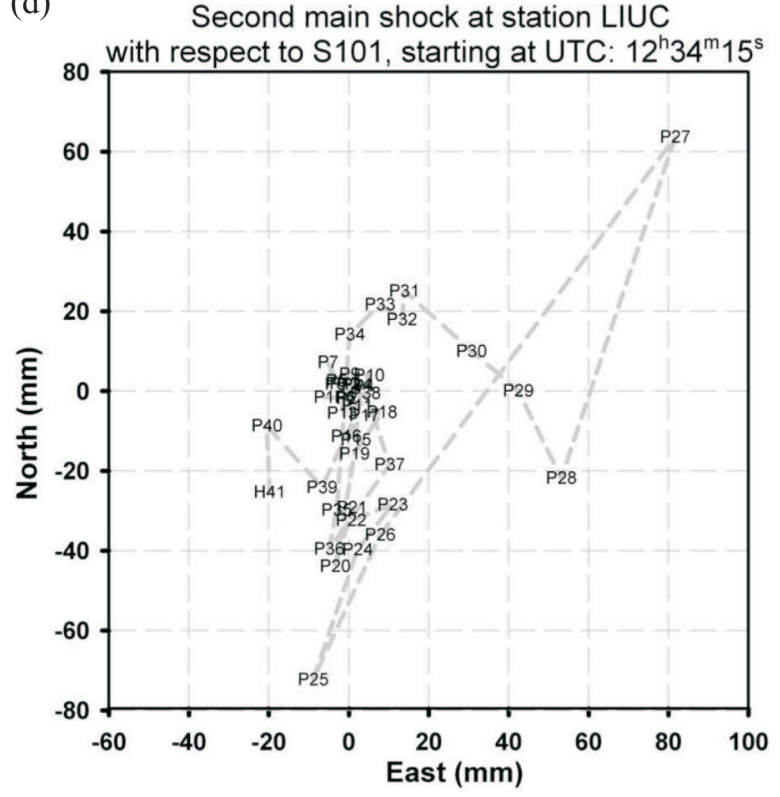

Fig. 8. Examples of evolution of the horizontal ground shaking for the first and second main shocks at stations HENC (A and B) and LIUC (C and D). The numbers in the diagram correspond to the time in second following the main shock. The first motion started tens to hundreds seconds after the main shock and generally coincides with the arrival time of the P-wave from the observation of seismometers.

was compared with the integration processing results from a nearby seismometer station TWKB, only a few kilometers away, of Academia Sinica. The ground motion recorded by the two different instruments showed a very similar pattern, with a good agreement for all three components for the first main shock (Fig. 7a) and the second main shock (Fig. 7b). The east and north components manifest the same trend but not as consistent in the up component. For instance, the ground motion near KDNM station went up to $10 \mathrm{~cm}$ in 18 seconds after the main shock in the east component, and the integra- tion processing from the seismometer acquires the same arrival time with the same amount of the ground motion.

\subsection{Attenuation of GPS Ground Shaking Motion}

We observed that the amplitude of the coseismic ground shaking, that is the maximum seismic ground motion, appeared to be in an exponential attenuation with the hypocentral distance. Thus, we applied a simple exponential relationship for the observed ground motion in the north, east 
Table 3. Maximum amplitudes of the seismic ground shaking motion and their arrival time for each component (north, east, up) of two main shocks of the 2006 Pingtung earthquake computed by $1 \mathrm{~Hz}$ GPS data in southern Taiwan.

\begin{tabular}{|c|c|c|c|c|c|c|}
\hline \multirow{2}{*}{ Stations } & \multicolumn{3}{|c|}{ Time after the main shock (sec) } & \multicolumn{3}{|c|}{ EQ1 (UTC: $\left.12^{\mathrm{h}} 26^{\mathrm{m}} 21.0^{\mathrm{s}}\right)$} \\
\hline & North & East & Height & $\mathrm{dN}(\mathrm{mm})$ & dE (mm) & dh (mm) \\
\hline CLON & 31 & 36 & 45 & $-43.3 \pm 7.9$ & $32.8 \pm 5.1$ & $46.3 \pm 15.6$ \\
\hline CTOU & 55 & 94 & 87 & $43.3 \pm 9.2$ & $45.0 \pm 7.4$ & $-34.7 \pm 13.8$ \\
\hline DAWU & 33 & 31 & 33 & $-25.9 \pm 9.0$ & $26.6 \pm 5.6$ & $-37.4 \pm 12.5$ \\
\hline DONA & 46 & 76 & 47 & $-27.7 \pm 9.1$ & $21.3 \pm 4.5$ & $26.3 \pm 13.0$ \\
\hline FALI & 28 & 31 & 36 & $-85.3 \pm 8.5$ & $49.0 \pm 5.1$ & $-44.7 \pm 12.5$ \\
\hline HENC & 19 & 19 & 22 & $-86.4 \pm 9.8$ & $-112.5 \pm 6.1$ & $-84.3 \pm 14.1$ \\
\hline JLUT & 26 & 25 & 31 & $-53.5 \pm 6.9$ & $-35.7 \pm 6.2$ & $57.8 \pm 15.8$ \\
\hline KDNM & 23 & 19 & 23 & $56.7 \pm 9.2$ & $-123.8 \pm 6.7$ & $-101.1 \pm 12.1$ \\
\hline LIUC & 29 & 47 & 52 & $-86.9 \pm 10.2$ & $-57.0 \pm 7.8$ & $-48.2 \pm 14.0$ \\
\hline NJOU & 45 & 38 & 44 & $42.7 \pm 8.6$ & $32.7 \pm 4.2$ & $45.4 \pm 15.0$ \\
\hline S01R & 61 & 94 & 93 & $-24.5 \pm 9.2$ & $14.3 \pm 5.9$ & $42.8 \pm 22.8$ \\
\hline S103 & 87 & 92 & 94 & $-17.4 \pm 5.8$ & $22.4 \pm 3.4$ & $-22.4 \pm 11.9$ \\
\hline SGAN & 51 & 65 & 47 & $46.8 \pm 7.9$ & $40.1 \pm 5.1$ & $34.1 \pm 11.9$ \\
\hline TSHO & 71 & 74 & 54 & $-57.4 \pm 10.2$ & $27.1 \pm 4.5$ & $30.4 \pm 15.6$ \\
\hline TMAM & 50 & 44 & 50 & $32.3 \pm 8.7$ & $27.3 \pm 5.5$ & $35.8 \pm 13.5$ \\
\hline YENC & 65 & 70 & 88 & $-38.7 \pm 8.5$ & $28.4 \pm 4.8$ & $-49.5 \pm 14.0$ \\
\hline \multirow{2}{*}{ Stations } & \multicolumn{3}{|c|}{ Time after the main shock (sec) } & \multicolumn{3}{|c|}{ EQ2 (UTC: $12^{\mathrm{h}} 34^{\mathrm{m}} 15.3^{\mathrm{s}}$ ) } \\
\hline & North & East & Height & $\mathbf{d N}(\mathbf{m m})$ & $\mathrm{dE}(\mathrm{mm})$ & dh (mm) \\
\hline CLON & 27 & 27 & 27 & $28.3 \pm 6.6$ & $-68.4 \pm 4.9$ & $58.5 \pm 15.7$ \\
\hline CTOU & 36 & 54 & 43 & $-45.8 \pm 8.2$ & $-27.0 \pm 5.8$ & $-31.7 \pm 14.4$ \\
\hline DAWU & 28 & 27 & 31 & $50.4 \pm 6.5$ & $-37.4 \pm 5.5$ & $-32.4 \pm 13.5$ \\
\hline DONA & 71 & 73 & 51 & $25.2 \pm 7.4$ & $13.1 \pm 6.2$ & $-22.6 \pm 15.4$ \\
\hline FALI & 28 & 32 & 40 & $-53.4 \pm 7.3$ & $-28.9 \pm 6.3$ & $30.1 \pm 13.5$ \\
\hline HENC & 25 & 28 & 24 & $-49.1 \pm 7.5$ & $-44.2 \pm 5.7$ & $-48.8 \pm 12.7$ \\
\hline JLUT & 25 & 26 & 30 & $22.5 \pm 7.8$ & $-52.7 \pm 5.8$ & $-41.0 \pm 16.1$ \\
\hline KDNM & 25 & 25 & 24 & $-45.1 \pm 8.1$ & $99.0 \pm 6.5$ & $58.1 \pm 13.5$ \\
\hline LIUC & 25 & 27 & 27 & $-75.2 \pm 8.3$ & $79.9 \pm 6.9$ & $-88.4 \pm 14.6$ \\
\hline NJOU & 47 & 28 & 51 & $-33.2 \pm 9.8$ & $-41.2 \pm 7.5$ & $-38.4 \pm 14.7$ \\
\hline S01R & 78 & 56 & 78 & $18.8 \pm 7.5$ & $13.5 \pm 5.1$ & $-30.2 \pm 15.8$ \\
\hline S103 & 94 & 89 & 109 & $13.7 \pm 5.7$ & $8.4 \pm 3.0$ & $-12.3 \pm 8.6$ \\
\hline SGAN & 37 & 32 & 47 & $42.8 \pm 9.8$ & $47.8 \pm 6.1$ & $26.6 \pm 11.7$ \\
\hline TMAM & 36 & 35 & 42 & $23.4 \pm 8.5$ & $-29.7 \pm 6.5$ & $-30.0 \pm 13.6$ \\
\hline TSHO & 59 & 70 & 57 & $-30.4 \pm 7.8$ & $26.8 \pm 6.8$ & $35.3 \pm 15.3$ \\
\hline YENC & 58 & 53 & 78 & $-18.1 \pm 8.5$ & $-27.4 \pm 7.9$ & $-31.9 \pm 12.7$ \\
\hline
\end{tabular}


and up components:

$$
Y(x)=Y_{0}+a \times \exp ^{-b x}
$$

where $Y_{0}$ is the initial value, $x$ is the relative distance from the hypocenter, $a$ is the amplitude coefficient associated with the decay function with decay parameter $b$.

Figure 9 shows the maximum amplitude of coseismic ground motion with respect to the hypocentral distance for 16 GPS stations with $1-\mathrm{Hz}$ data for the Pintung earthquakes. We obtained the best fits of the Equ. (1) for north, east, and up component for different values of $a$ and $b$. For the first main shock, the amplitudes of the ground motion of the GPS stations, except for the station LIUC, fit well with the hypocentral distance (Fig. 9a), with the nearest station HENC showing the largest amplitude of seismic ground motion in all three components. For the second main shock (Fig. 9b), a good agreement of the relationship can also be found, with largest seismic ground motion occurring in the station LIUC in all three components.

In order to better elucidate the attenuation behavior, we also estimated the arrival time of the maximum amplitude of the ground shaking following the main shocks (Table 4). By applying a linear polynomial and an exponential function, the arrival time versus the distance from the hypocenter shows a good linear relationship for both two main shocks (Fig. 10). On the other hand, although the amplitudes of the first ground motions decay basically with distance, there seems to appear two groups with different decaying behaviors, especially for the second main shock (Fig. 10b). As illustrated in Fig. 10, four stations, including LIUC, SGAN, CTOU, and TSHO, show lager amplitudes of ground motion (i.e., the upper short dash line) for both two main shocks. We found that these four stations all are located in the western coastal plain, suggesting a possible enhancing effect of the thick unconsolidated deposits in the western coastal plain. On the other hand, the stations located in the foothills and mountain range, which fit to the lower decaying curve in Fig. 10b, exhibit smaller amplitude of ground shaking.

\section{CONCLUSION}

We applied both kinematic and daily solution algorithms to data from 17 continuous GPS stations with $1-\mathrm{Hz}$ sampling and 300 stations with 30-second sampling rate, respectively, to study two sequential large earthquakes $\left(\mathrm{M}_{\mathrm{L}}\right.$ $=6.96$ and 6.99) at an interval of 8 minutes that occurred in (a)

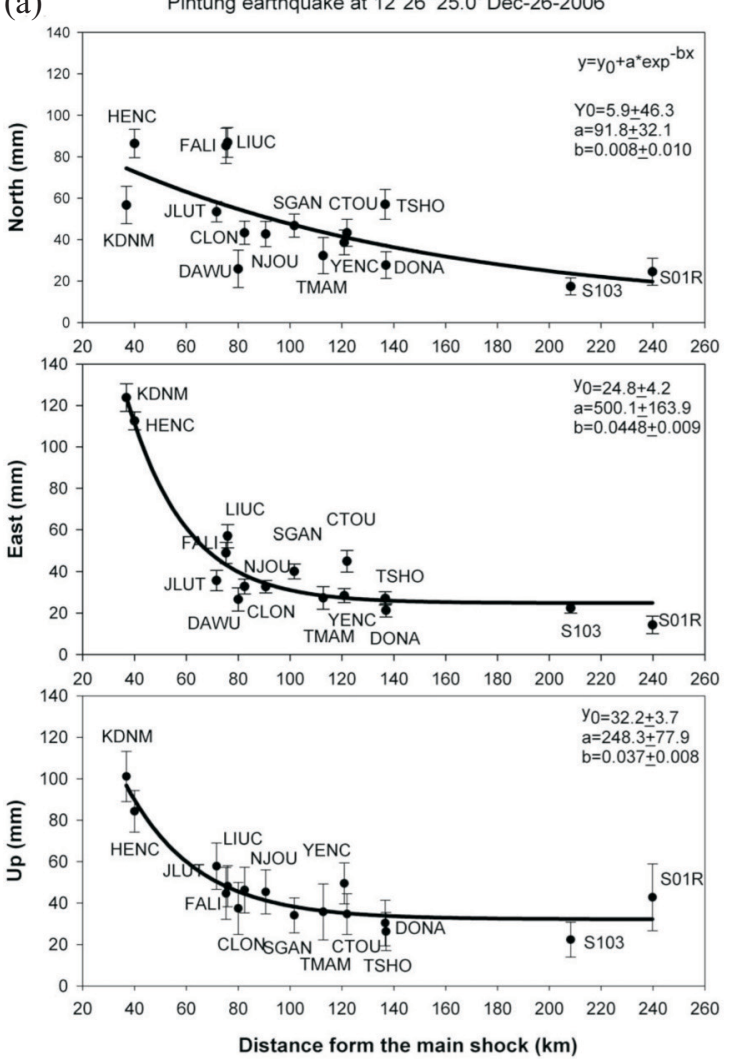

(b)
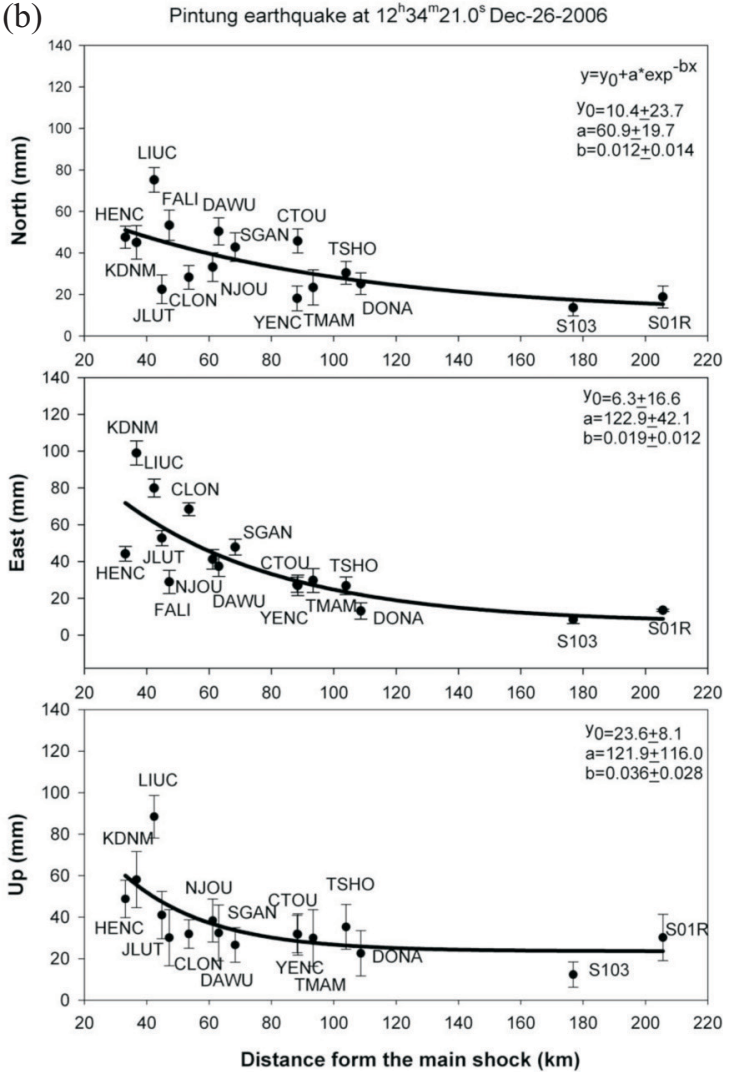

Fig. 9. Attenuation behavior of the coseismic ground shaking illustrated by the maximum amplitudes of ground shaking with respect to the hypocentral distance for (a) the first main shock and (b) the second main shock. The relationship showed that it can generally be expressed by an exponential decay function for each of the three components (north, east, up). 
Table 4. The first maximum amplitudes of the horizontal seismic ground shaking motion and their arrival time, determined by epoch by epoch solutions from $1 \mathrm{~Hz}$ GPS data for each of the two main shocks of the Pingtung earthquake.

\begin{tabular}{|c|c|c|c|c|c|c|}
\hline \multirow[t]{2}{*}{ Stations } & \multicolumn{3}{|c|}{ Main shock 1 (UTC: $\left.12^{\mathrm{h}} 26^{\mathrm{m}} 21.0^{\mathrm{s}}\right)$} & \multicolumn{3}{|c|}{ Main shock 2 (UTC: $\left.12^{\mathrm{h}} 34^{\mathrm{m}} 15.3^{\mathrm{s}}\right)$} \\
\hline & Time after MS1 (sec) & Disp.(mm) & Azi $\left({ }^{\circ}\right)$ & Time after MS2 (sec) & Disp.(mm) & Azi $\left({ }^{\circ}\right)$ \\
\hline$\overline{\mathrm{CLON}}$ & 31 & $48.0 \pm 6.6$ & $154 \pm 5$ & 27 & $77.6 \pm 5.7$ & $307 \pm 3$ \\
\hline CTOU & 41 & $41.9 \pm 8.3$ & $156 \pm 7$ & 36 & $41.3 \pm 7.1$ & $147 \pm 6$ \\
\hline DAWU & 33 & $27.5 \pm 7.5$ & $160 \pm 6$ & 28 & $54.6 \pm 6.8$ & $304 \pm 12$ \\
\hline DONA & 46 & $30.1 \pm 7.2$ & $159 \pm 7$ & 37 & $14.4 \pm 6.8$ & $323 \pm 19$ \\
\hline FALI & 28 & $85.4 \pm 9.4$ & $177 \pm 4$ & 26 & $54.6 \pm 6.6$ & $168 \pm 7$ \\
\hline HENC & 19 & $136.8 \pm 9.4$ & $231 \pm 3$ & 26 & $49.7 \pm 6.6$ & $189 \pm 5$ \\
\hline JLUT & 26 & $55.6 \pm 6.6$ & $196 \pm 5$ & 26 & $54.1 \pm 6.9$ & $283 \pm 6$ \\
\hline LIUC & 29 & $88.6 \pm 9.1$ & $168 \pm 4$ & 27 & $104.4 \pm 5.6$ & $50 \pm 3$ \\
\hline KDNM & 19 & $133.9 \pm 8.7$ & $121 \pm 4$ & 25 & $108.8 \pm 6.5$ & $204 \pm 5$ \\
\hline NJOU & 33 & $38.1 \pm 6.8$ & $132 \pm 7$ & 28 & $34.5 \pm 7.6$ & $266 \pm 11$ \\
\hline S01R & 61 & $20.7 \pm 7.7$ & $29 \pm 13$ & 57 & $15.5 \pm 6.5$ & $36 \pm 11$ \\
\hline S103 & 55 & $14.9 \pm 4.8$ & $128 \pm 14$ & 51 & $14.6 \pm 4.5$ & $193 \pm 9$ \\
\hline SGAN & 36 & $48.1 \pm 6.7$ & $135 \pm 6$ & 32 & $48.5 \pm 8.1$ & $80 \pm 8$ \\
\hline TMAM & 44 & $28.0 \pm 7.5$ & $77 \pm 7$ & 36 & $34.8 \pm 7.2$ & $318 \pm 9$ \\
\hline TSHO & 45 & $38.2 \pm 7.9$ & $138 \pm 8$ & 37 & $27.0 \pm 7.3$ & $173 \pm 10$ \\
\hline YENC & 41 & $29.0 \pm 6.9$ & $144 \pm 9$ & 36 & $18.2 \pm 8.2$ & $134 \pm 18$ \\
\hline
\end{tabular}
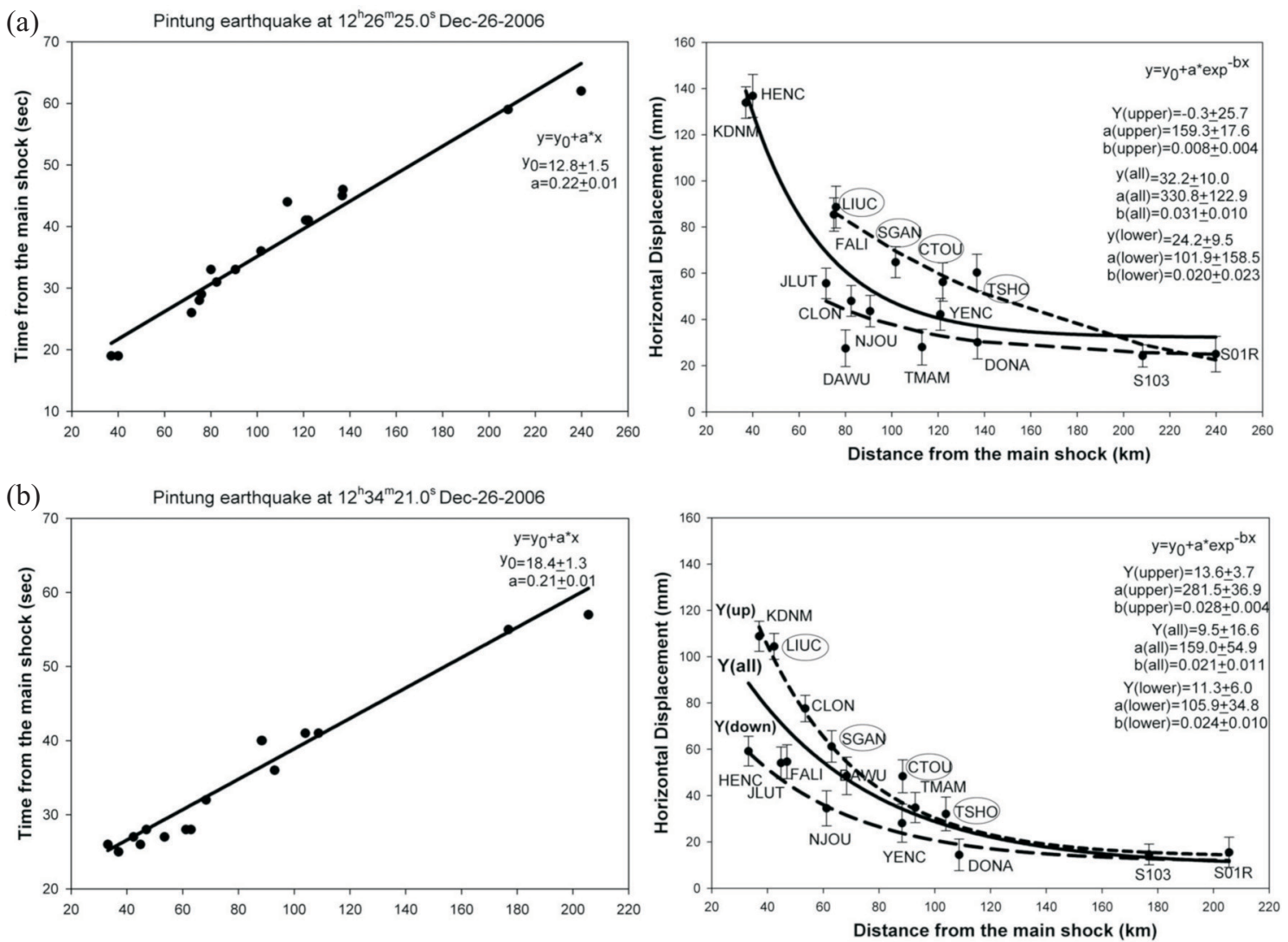

Fig. 10. Relationship between the affected time and the first largest horizontal ground motion and its attenuation with respect to the hypocentral distance for (a) the first main shock and (b) the second main shock. Four stations in the western coastal plain, LIUC, CTOU SGAN, and TSHO (marked by outlined frame), appear to have larger ground shaking during both main shocks. 
southern Taiwan offshore Hengchun on 26 December 2006. By combining the daily solutions calculated from 30 -second data, we obtained the total coseismic displacements, indicating only three stations near the epicenters with significant coseismic movements of $3-5$ centimeters. Based on the $1-\mathrm{Hz}$ data, we estimated individual coseismic displacements in southern Taiwan for the two main shocks. Our results showed different deformation patterns that are generally in agreement with a focal mechanism of NNW-trending normal faulting for the first main shock, and ENE-trending (or less likely NNW-trending) strike-slip faulting for the second. We observe that the stations north of the epicenters area had opposite movements during the two main shocks, suggesting a possible elastic rebound of the second main shock responding to the first main shock. We argue that the first shock resulted from E-W extension in the lower crust due probably to the break-up in the eastward subduction, and that the second shock occurred by prompt response of the $\mathrm{E}-\mathrm{W}$ compression in the shallower crust due to collision from plate convergence.

The 1-Hz GPS data indicate that coseismic ground shaking can be recorded by GPS stations in great detail. We observe that the first significant movement of the ground shaking began tens of seconds following the main shocks, generally coinciding with the arrival time of the $\mathrm{P}$-wave, and moved toward the similar direction of the finite coseismic displacement before the movement going back and forward. The maximum amplitudes of the ground shaking due to the Pingtung earthquake seem to follow an attenuation behavior with an exponential decay with hypocentral distance. The stations located in the western coastal plain generally reveal relatively larger amplitudes of ground shaking. We interpret it as an enhancing effect of ground shaking due to thick unconsolidated deposits in the coastal plain area.

Acknowledgements The generous provision of continuous GPS data by the CWB, MOI as well as precise ephemeredes of the GPS satellites by the IGS community are greatly appreciated. The authors express sincere gratitude to colleagues in the Geodetic Group at IESAS for their contributions to the acquisition of the GPS data from the permanent stations. Wen-Tzong Liang kindly prepared and provided the seismometer data. Helpful reviews with constructive comments and English editing by B. F. Chao and an anonymous reviewer have greatly improved the manuscript. This research was supported by the Taiwan Earthquake Research Center (TEC) funded through National Science Council with grant number NSC95-2119-M-001-055 and is a contribution of the Institute of Earth Sciences, Academia Sinica. The TEC contribution number for this article is 00044.

\section{REFERENCES}

BATS (Broadband Array in Taiwan for Seismology), http:// bats.earth.sinica.edu.tw/.

Bock, Y., R. M. Nikolaidis, P. J. de Jonge, and M. Bevis, 2000: Instantaneous geodetic positioning at medium distances with the Global Positioning System. J. Geophys. Res., 105, 28223-28253.

Chen, H. Y., L. C. Kuo, W. S. Chuang, and S. B. Yu, 2003: Using Quasi Ionosphere-Free post-processing algorithm on the medium-range kinematic high accuracy GPS relative positioning. Wuhan Univ. J. Natl. Sci., 8, 2B, 610-618.

CWB (Central Weather Bureau), 2007: Earthquake report. http:// www.cwb.gov.tw/.

Dach, R., U. Hugentobler, P. Fridez, and M. Meindl, 2007: Bernese GPS software Version 5.0, Astronomical Institute, University of Bern, Switzerland, 612 pp.

Dong, D., P. Fang, Y. Bock, F. Webb, L. Pramirodirdjo, S. Kedar, and P. Jamason, 2006: Spatiotemporal filtering using principal component analysis and karhunen-Lover expansion approaches for regional GPS network analysis. $J$. Geophys. Res., 111, B03405, doi: 10.1029/2005JB003806.

Ge, L., S. Han, C. Rizos, Y. Ishikawa, M. Hoshiba, Y. Yoshida, M. Izawa, N. Hashimoto, and S. Himori, 2000: GPS seismometers with up to $20 \mathrm{~Hz}$ sampling rate. Earth Planets Space, 52, 881-884.

Hatanaka, Y., H. Tsuji, Y. Abe, Y. Iimura, K. Kobayashi, and H. Morishita, 1994: Coseismic crustal displacements from the 1994 Hokkaido-Toho-Oki earthquake revealed by a nationwide continuous GPS array in Japan - results of GPS kinematic analysis. Japanese Symposium on GPS 1994, Tokyo, Japan, 15-16 December, 141-147. (in Japanese)

IESAS (Institute of Earth Sciences, Academia Sinica), 2007: http://gps.earth.sinica.edu.tw/.

Kuo, L. C., 2001: High Precision GPS Surveying for Crustal Deformation Study. Ph.D. Thesis, Department of Civil Engineering, National Chiao-Tung University, Hsinchu, Taiwan, ROC, 201 pp. (in Chinese)

TEC (Taiwan Earthquake research Center), 2007: http://tec .earth.sinica.edu.tw/workshop/.

Yu, S. B. and H. Y. Chen, 1994: Global Positioning System measurements of crustal deformation in the Taiwan arccontinent collision zone. Terr. Atmos. Ocean. Sci., 5, 477498. 